\title{
РАСПРЕДЕЛЕНИЕ ГЛАУКОНИТА В ГРАНУЛОМЕТРИЧЕСКИХ ФРАКЦИЯХ ПОРОД НИЖНЕГО КЕМБРИЯ ЭСТОНИИ
}

Глауконит является наиболее характерным аутигенным минералом для всего разреза осадочных пород нижнего кембрия Прибалтийского региона, несмотря на то, что его содержание в породе редко превышает $1-3 \%$ (Рейер, 1967; Фирсов и др., 1971). В породе он распределяется очень неравномерно и в основном скапливается на отдельных поверхностях наслоения, в косослоистых сериях и в присыпках, в тонких алевритовопесчаных линзах, в гнездах, в материале, заполняющем карманообразные углубления в подошве слоев, а также в ходах илороющих организмов. Такое распространение, а также гранулярная форма минерала указывают на возможность существования в породах аллохтонных форм залегания глауконита.

Это обстоятельство позволяет при более подробном рассмотрении отношения глауконита и сугубо кластогенных компонентов пород проследить количественное распределение глауконита по всему гранулометрическому спектру отложений, выявить основные глауконитоносные фракции и оценить абсолютные массы минерала, поступающие в осадки в составе той или иной фракции. Эти вопросы, хотя и являются ключевыми в распознавании генезиса глауконита в терригенных осадочных образованиях, весьма слабо затронуты в геологической литературе: обычно приводятся лишь данные о преобладающем размере зерен глауконита, реже рассматривается распределение минерала по всему спектру породы (Формозова, 1949; Лазаренко, 1956). В этой связи данные настоящего сообщения, в котором изложены результаты изучения распределения глауконита в породах основных трех подразделений нижнего кембрия материковой части Эстонии, могут представить более общий интерес.

Изучению подвергались 56 проб из пород лонтоваской, люкатиской и тискреской свит в их современном понимании (Менс, Пиррус, 1977). При этом были исследованы как обогащенные глауконитом образцы, так и обычные фоновые пробы. Во фракциях $>0,01$ мм в иммерсии или под бинокуляром было подсчитано 400-600 минеральных зерен, на основе которых устанавливалось процентное содержание глауконита в каждой фракции. При этом не учитывались недиспергированные агрегатные частицы минералов, а также аутигенные карбонаты и сульфиды. Фракции $<0,01$ мм не изучались из-за трудностей диагностики тонкодисперсного глауконита, хотя наличие этого минерала в пелитовой части некоторых пород весьма вероятно (Pralow, 1938).

Гранулометрическое фракционирование проводилось набором сит $0,05,0,1,0,25,0,5$ и 1,0 мм после удаления отмучиванием частиц

I ENSV TA Toimetised. G 31979

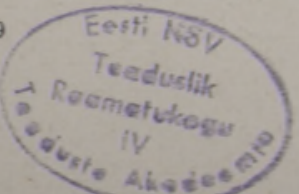


$<0,01$ мм. Количество глауконита в отдельных фракциях вычислялось по методике Л. Б. Рухина (1961), т. е. путем умножения процентного содержания соответствующей фракции в пробе на содержание в ней глауконита и последующего пересчета полученных данных на $100 \%$.

Поскольку за основу расчетов во всех случаях были взяты результаты визуального подсчета зерен, то в некоторых пробах было проведено параллельно прямое взвешивание мономинерализованного глауконита. Оказалось, что в случае присутствия большого количества агрегатных, недиспергированных частиц породы визуально определенная масса минерала на $50-60 \%$ ниже действительной. При обычном незначительном содержании агрегатных частиц относительная ошибка определения составляет $\pm 10 \%$. Наоборот, при повышенной микропористости зерен глауконита, как, например, у светло-зеленых разрыхленных зерен из базальной пачки лонтоваской свиты, масса глауконита может быть визуально переоценена в 2 раза. Все это показывает, что полученные данные являются сравнительно неточными и могут быть использованы лишь с некоторой условностью. Неточность определения усугубляется еще и частичным раздроблением зерен глауконита при подготовке проб к анализу, чего практически нельзя учесть.

Тем не менее, систематический характер ошибок и, прежде всего, сравнительно низкие исходные содержания глауконита в породах значительно снижают значение этих погрешностей; во всяком случае, они не могут затушевывать выявленные принципиальные закономерности, представленные к рассмотрению ниже.

В наиболее древнем изученном подразделении нижнего кембрия Эстонии - лонтов а ской свите - глауконит широко распространен в прослоях песчаников базальной сямиской пачки. По данным исследования 9 образцов максимальное содержание глауконита наблюдается в мелко- или крупноалевритовой фракцин. Реже отмечается появление второго максимума в мелко- или среднепесчаной фракции (рис. 1,49 ). Интересным представляется обычное отсутствие глауконита в гравийной фракции, которая составляет значительную часть в отдельных разновидностях песчаников (Pirrus, Rätsep, 1977). Таким образом, наиболее обогащенными глауконитом являются второстепенные алевритовые фракции песчаников. Эта закономерность прослеживается, как видно ниже, почти по всему разрезу нижнего кембрия Эстонии.

В глинах лонтоваской свиты содержание глауконита во фракциях $>0,01$ мм зависит прежде всего от количества этих фракций в породе. Так, у более дисперсных глин распределение глауконита по грубым фракциям весьма сложное и в целом характеризуется низкими содержаниями его. В глинах с грубообломочной примесью содержание глауконита достигает максимума во фракциях $0,1-0,25$ или $0,25-0,50$ м.и (рис. $1,40,42-45)$. Принципиально близкое к вышеописанному распределение глауконита наблюдается и в неотсортированных песчано-глинистых микстолитах (рис. 1,53 ). Таким образом, и в глинах максимум концентрации глауконита значительно сдвинут относительно породообразующих фракций, но по сравнению с песчаниками в противоположную сторону.

Для переслаивающихся глин и алевролитов люк а т и с о й с в и ты глауконит является еще более характерным минералом и встречается в них как в виде рассеянных зерен, так и в виде богатых скоплений на плоскостях напластования, в гнездах и в седиментационных ловушках. В глинах с фоновым содержанием глауконита наиболее обогащенными являются либо крупноалевритовая, либо мелкопесчаная фракции (рис. 1, $19,22,24)$. В глинах и алевролитах с повышенным содержанием глауко- 
нита можно отметить два типа распределения. В наиболее простом случае концентрация глауконита постепенно возрастает до размерности среднего песка и затем уменьшается в более грубых фракциях (рис. 1, $18,21,23,26,27,29)$. Для второго типа характерны два максимума первый, основной, в мелкопесчаной, второй - в мелкоалевритовой фракции (рис. $1,17,20,25,28,31,32$ ). В последнем случае в пробах обычно наблюдается большое количество агрегатных зерен глауконита, т. е. здесь более мелкие зерна минерала объединены в гранулы, по размеру равные гранулам песка. Возможно, что наличие двух максимумов объясняется в данном случае вторичными явлениями в осадке. Важно отметить, что распределение первого типа присуще линзо- или гнездовидным скоплениям глауконита в глинах, а распределение второго типа алевролитовым прослоям и линзам с послойным расположением глауконита.

Таким образом, в материале люкатиской свиты обогащенность глауконитом прослеживается в основном в песчаных фракциях. Это свидетельствует о том, что значительная часть люкатиского глауконита формировалась в виде крупных аутигенных агрегатов. Однако присутствие в скоплениях глауконита фосфатизированной гальки и скелетных остатков фауны явно указывает на то, что первичные аутигенные образования глауконита неоднократно перемещались на морском дне до окончательного захоронения в осадке. Следовательно, именно механическому фактору седиментогенеза принадлежит ведущая роль в концентрировании или рассеивании минерала в отложениях свиты.

В алевролитах тискреской свиты глауконит редко образует богатые скопления; обычно этот минерал присутствует в виде рассеянных зерен. Тип его распределения по фракциям зависит не от положения породы в разрезе, а прежде всего от степени обогащенности алевролита глауконитом. Так, более обогащенные глауконитом породы обычно обладают двумя максимумами концентрации - во фракции тонкого алеврита $(0,01-0,05$ мм) и в песчаных фракциях (рис. $1,5,8,16)$. Более бедные глауконитом образцы, отобранные, как правило, из глинистых участков разреза, характеризуются одним концентрационным максимумом в интервале от крупного алеврита до среднезернистого песка (0,05-0,5 мм). Многие хорошо отсортированные алевролиты тискреской свиты содержат лишь редкие зерна глауконита, приуроченность которых к какой-либо фракции еще не выяснена.

Изложенное выше свидетельствует о том, что наибольшие содержания глауконита в породах нижнекембрийского разреза Эстонии встречаются именно в тех гранулометрических фракциях, которые не являются породообразующими (рис. 2). Поскольку эта закономерность действительна для всех типов отложений, можно сделать вывод о руководящем процессе глауконитонакопления в этих бассейнах, заключающемся в разбавляющем, подавляющем влиянии привноса обломочного материала. Наиболее заметно оно проявляется при хорошо отсортированных породах разреза. Следовательно, аутигенное глауконитообразование было в этих водоемах непрерывным фоновым процессом, постоянно высаждающим микроконкреционные гранулы различной размерности. Поступление в бассейн какого-либо обломочного материала мешало, несомненно, более или менее равномерному распределению глауконита в осадке и сводило до минимума его содержание именно в той фракции, которая соответствовала максимуму гранулометрического состава привнесенного обломочного материала.

Этот принципиально простой ход глауконитонакопления иногда осложнялся другими процессами, например, усиленным образованием 
ТИСКРЕСКАЯ СВИТА
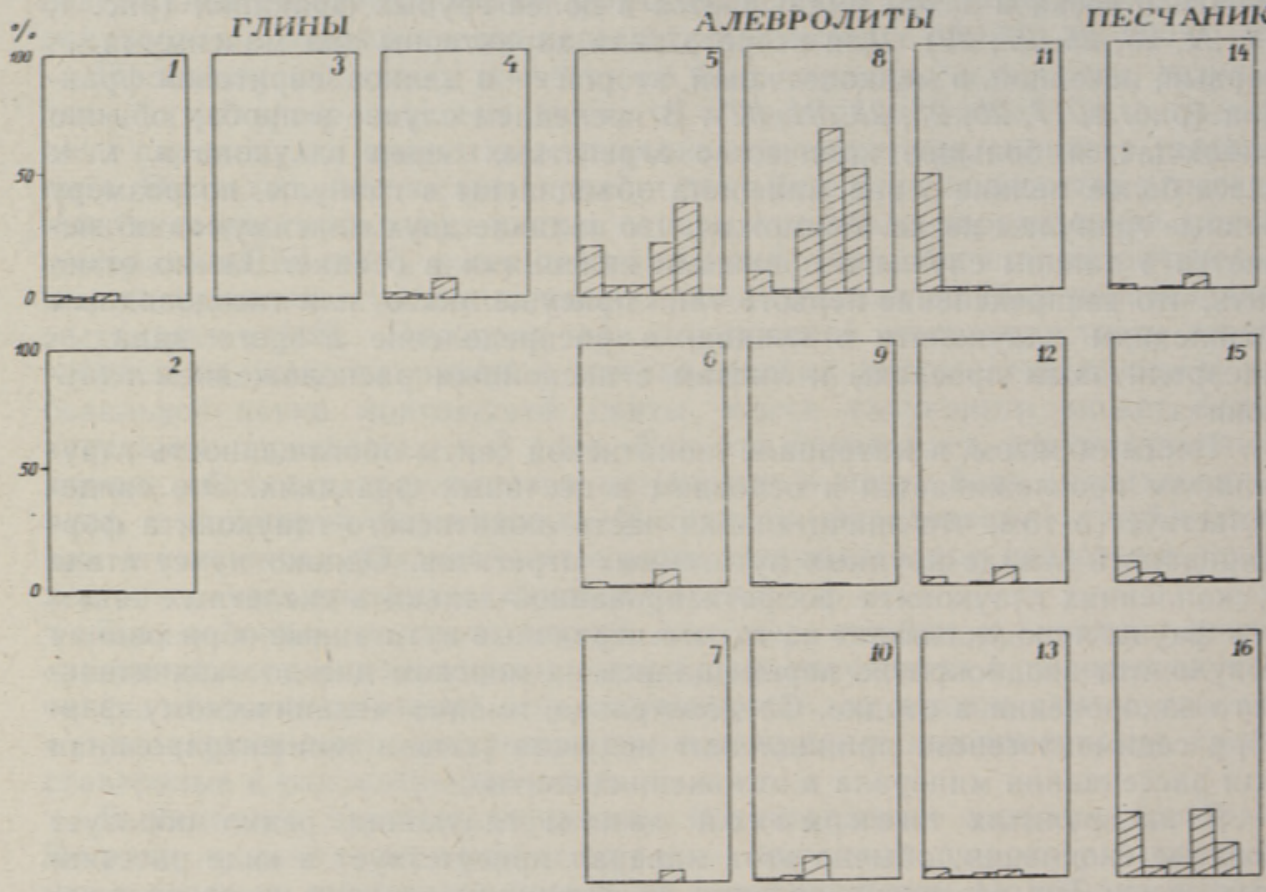

ЛЮКАТИСКАЯ СВИТА

глины
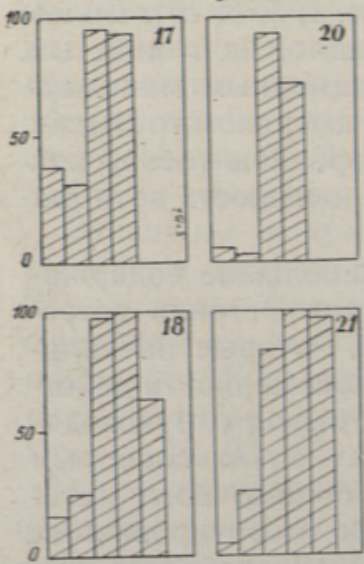

$x$

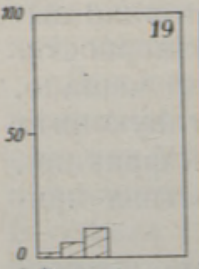

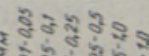

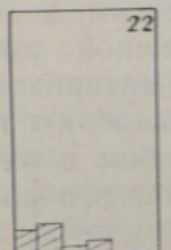

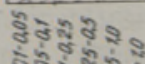

АЛЕВРОЛИТЬІ
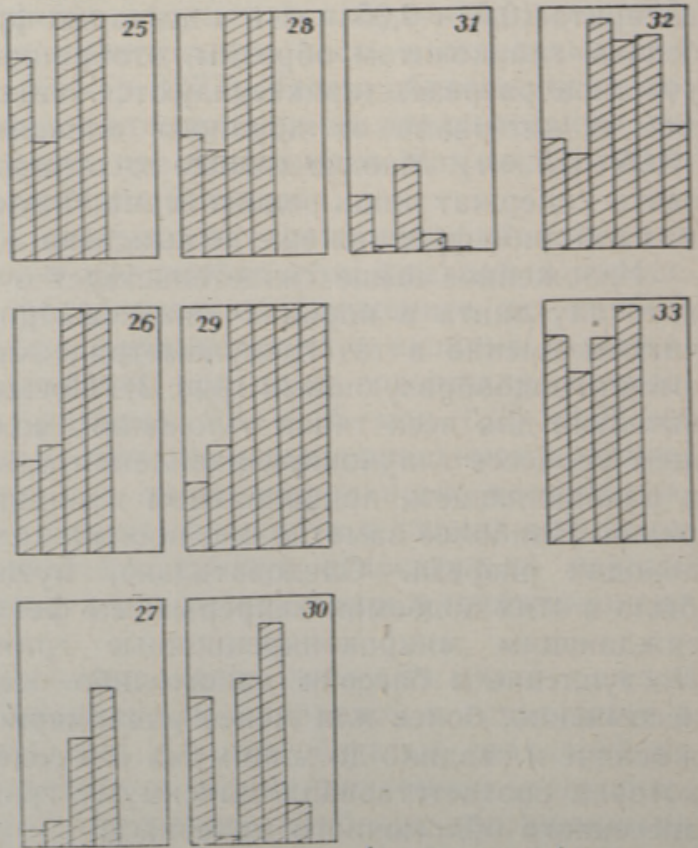

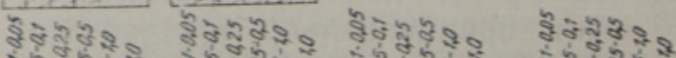

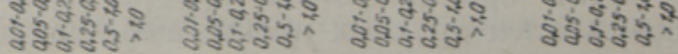

ПЕСЧАНИКИ
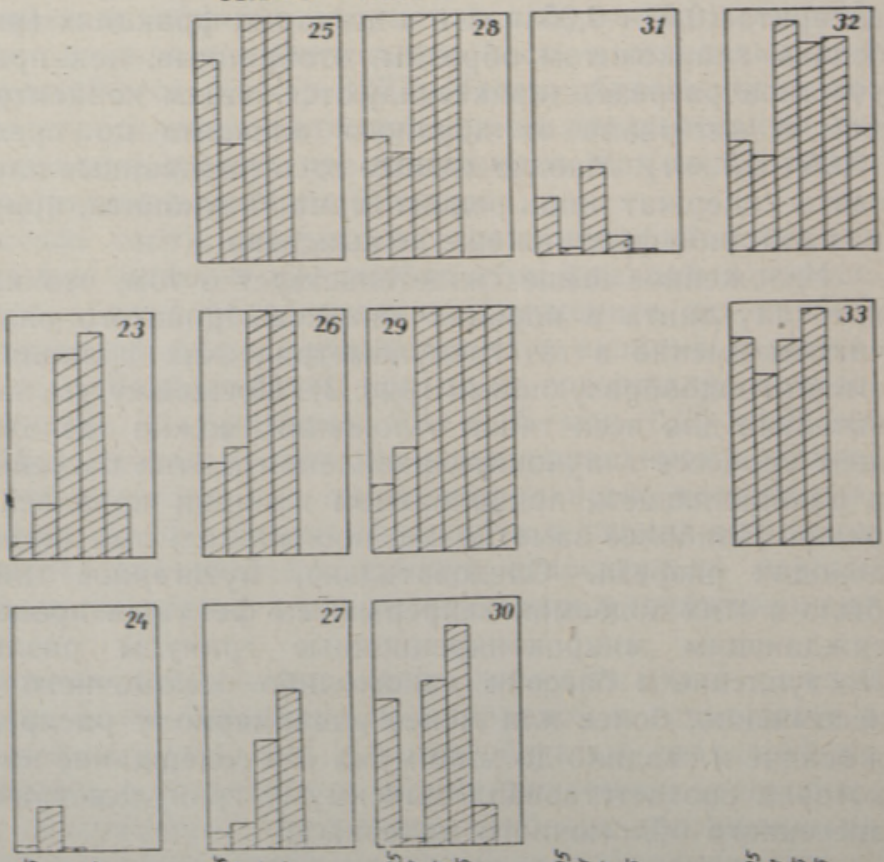

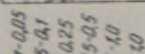

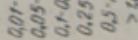




\section{ЛОНТОВАСКАЯ СВНТА}

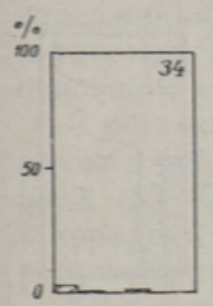

\section{гллины}
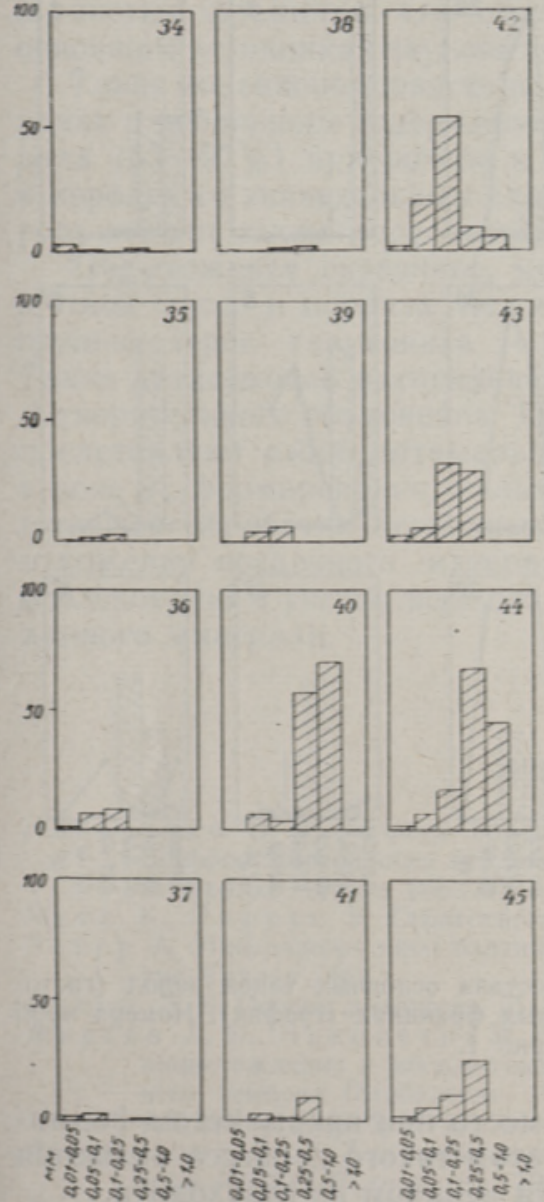

क्षेत्रेक्षेक

\section{ПЕСЧАНИКИ}
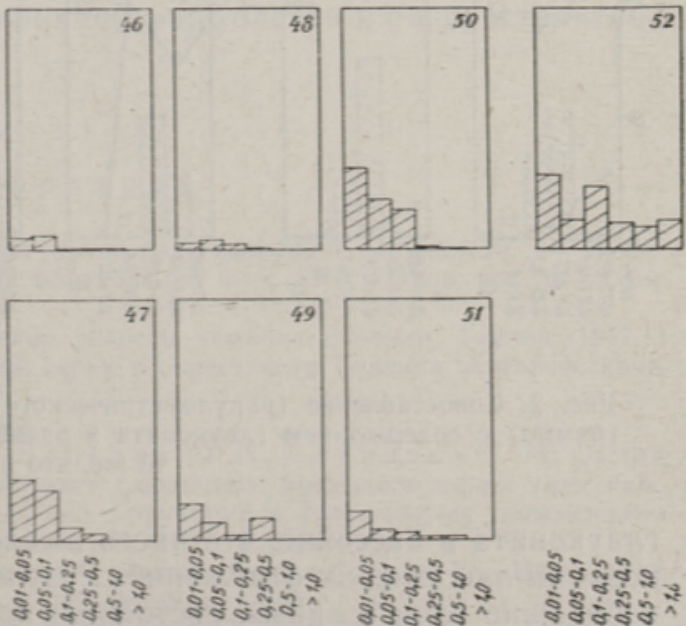

Рис. 1. Содержание глауконита в грубообломочных фракциях нижнекембрийских отложений Эстонии.

$1-4-$ обн. Хййемяэ; 5 - обн. Тоолсе; 6 - обн. Тойла-Онтика; 7 - скв. Румба, гл. 291,0 м; 8 - обн. Тоолсе; 9 - обн. Раннамыйза; 10 - скв. Эссу, гл. 60,0 м; 11 - обн. Вока; 12 - обн. Хийемяэ; 13 - обн. Мустаметса; 14 - скв. Эссу, гл. 53,0 м; $15-$ обн. Утрия; 16 - обн. Мустаметса; 17 - обн. Савиранна; 18 - обн. Кунда; 19 - скв. Колувере, гл. 242,0 ж; 20 - скв. Эссу, гл. 68,0 м; 21 - скв. Коэравере, гл. 143,0 $м$; 22 - скв. Румба, гл. 299,0 м; 23 - обн. Вока-Пяйте; 24 - скв. Эссу, гл. 63,0 м; 25 обн. Колгакюла; 26 - обн. Кунда; 27 - скв. Виру-Роэла, гл. 182,0 29 - обн. р. Кунда; 30 - обн. Пяйте; 31 - обн. Онтика; 32 - обн. Вока; 33 - обн. Мустаметса; 34 - скв. Румба, гл. 305,0 м; 35 - скв. Колувере, гл. 251,0 м; 36 - скв. Эссу, гл. 124,0 м; 37 - скв. Румба, гл. 370,0 м; 38 - скв. Румба, гл. 315,0 м; 39 - скв. Эссу, гл. 115,0 ж; 40 - скв. Кунда, гл. 38,0 $⿻ ; 11$ - скв. Колувере, гл. 295,0 s; $42-$ скв. Арукюла, гл. 95,0 м; 43 - скв. Эссу, гл. 84,0 м; 44 - скв. Петсери, гл. 490,0 м; 45 - скв. Петсери, гл. 508,0 м; 46 - скв. Эссу, гл. $141,0 . s ; 47$ - скв. Аре, гл. 420,0 ; 48 - скв. Эссу, гл. 128,0 s; 49 - скв. Румба, гл. $360,0 s ; 50$ - скв. Кавасту, гл. 158,0 ; 51 - скв. Петсери, гл. 494,0 м; 52 - скв. Парила, гл. 149,0 м; 53 - скв. Петсери, гл. 492,0 ‥ 


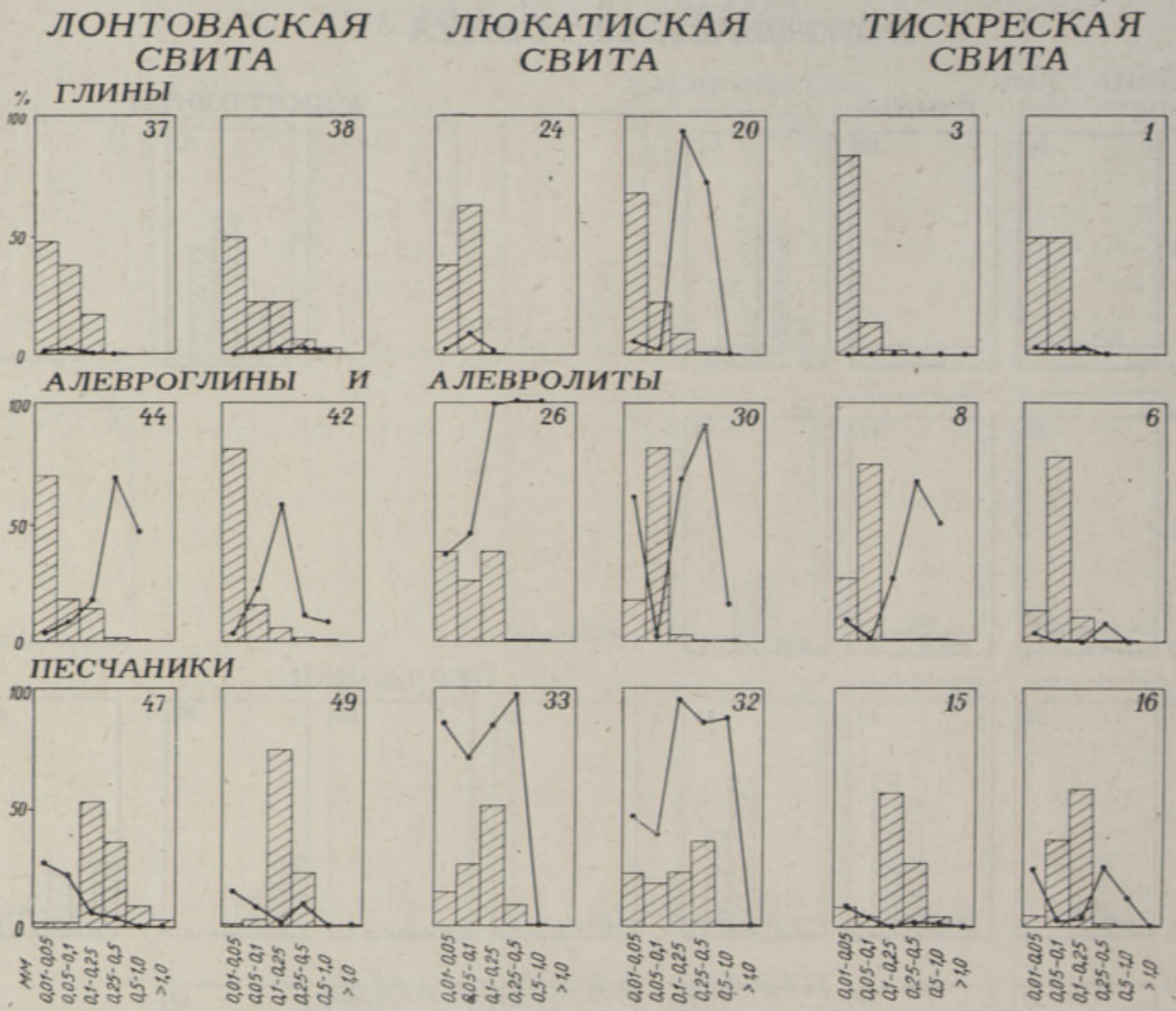

Рис. 2. Сопоставление гранулометрического состава основных типов пород (гистограмма) с содержанием глауконита в размерных фракциях (график). Номера проб те же, что на рис. 1.

глауконита в бассейне, что часто имело место при прерывистом формировании люкатиских отложений. Результатом такого процесса являются небольшие слои и линзы, состоящие почти целиком из глауконита.

Расчеты с учетом концентрации глауконита в отдельных фракциях и количественной роли этих фракций в гранулометрическом спектре породы показывают, что в песчаниках базальной пачки лонтоваской свиты основная масса глауконита содержится в мелкопесчаной фракции $(0,1-0,25$ мм), реже в среднезернистом песке $(0,25-0,5$ мм) или крупном алеврите $(0,05-0,1$ мм), т. е. в главной породообразующей фракции или фракции на одну ступень ниже. Обратное наблюдается редко. Общая масса глауконита в этих песчаниках варьирует в широких пределах - от 0,5 до 9,9\%. Глины лонтоваской свиты значительно беднее глауконитом $(0,01-0,02 \%)$, и основная масса минерала связана в них с мелко- и крупноалевритовой фракцией. Лишь при значительном содержании в глине алевритово-песчаного материала отмечается перемещение количественного максимума в мелко- или ореднепесчаную фракцию.

Для отложений люкатиской свиты с низким $(0,02-9,8 \%)$ содержанием глауконита наиболее характерно скопление основной массы минерала $(75-97 \%)$ в мелкоалевритовой фракции. При повышении содержания глауконита во всей породе до $30 \%$ наблюдается распределение основной массы глауконита между мелкоалевритовой $(0,01-0,05$ мм) и мелкопесчаной $(0,1-0,25$ мм) фракциями. В сильно обогащенных 
глауконитом породах $(30-65 \%)$ наибольшее количество глауконита содержится в песчаных фракциях. Таким образом, наряду с увеличением содержания минерала, закономерен сдвиг глауконитоносности к крупнозернистым фракциям, что, очевидно, подчеркивает роль аутигенеза как основного источника глауконита в отложениях свиты.

Такая же закономерность прослеживается и в тискреской свите: в породах с небольшим содержанием глауконита основное количество минерала (65-97\%) приурочено к мелко- или крупноалевритовой фракции; в породах со значительным (до $5 \%$ ) содержанием глауконита заметную роль играют также мелкопесчаные фракции.

Подытоживая сказанное, можно сделать вывод о том, что по абсолютной массе в породах нижнего кембрия Эстонии превалируют две группы зерен глауконита - мелкоалевритовая и (мелко)песчаная. Такое двухпиковсе распределение минерала не нашло себе пока удовлетворительного объяснения. Трудно предположить, что эти размерности представляют собой оптимальные величины новообразований минерала в зоне их формирования; нельзя, очевидно, недооценивать фактор механической обработки первичных аутигенных образований в цикле переотложения осадочного материала. Вопрос этот требует дальнейшего исследования с учетом всех особенностей морфологии и распространения данного минерала.

\section{ЛИТЕРАТУРА}

Л а з а рен ко Е. К. Вопросы номенклатуры и классификации глауконита. - В кн.: Вопросы минералогии осадочных образований $3-4$. Изд. Львов. гос. ун-та им. И. Франко, 1956, с. $345-379$.

Менс К., Пир ус Э. Стратотипические разрезы кембрия Эстонии. Таллин, 1977. Р ей е р А. Минералогия глин балтийской серии в окрестности Таллина. Автогеф. канд. дис. Таллин, 1967.

Р ухин Л. Б. Основы литологии. Л., 1961.

Фи рсов Л. В., Ни колаева И. В., Лебедев Ю. Н., Солнцев а С. М. Состав, происхождение и абсолютный возраст слюдистых минералов синих глин нижнего кембрия Прибалтики. - В кн.: Глауконит в современных, нижнепалеозойских и докембрийских отложениях. М., 1971, с. 165-192.

Фор мозов а Л. Н. Глауконитовые пески урочища Кызыл-Сай. - Тр. Ин-та геол. наук АН СССР, геол. сер., 1949, т. 112, № 38, с. 1-83.

Pirrus E., Rätse p. M. Kruusaterad Eesti vanimais settekivimeis. - Eesti Loodus, 1977, nr. 4, Ik. $231-234$.

Pralow W. Mikroskopische, röntgenographische und chemische Untersuchung einiger Proben des estländischen blauen Tons. - Chemie der Erde, 1938, Bd. 11 , H. 4, S. $480-497$.
Институт геологии
Академии наук Эстонской ССР
Поступила в редакцию
23/V 1978

\section{RATSEP}

\section{GLAUKONIIDI JAOTUS EESTI ALAMKAMBRIUMI KIVIMITE GRANULOMEETRILISTES FRAKTSIOONIDES}

Artikkel sisaldab andmeid Eesti alamkambriumi lontova, lükati ja tiskre kihistu eri kivimitüüpidest vōetud 56 proovi granulomeetriliste fraktsioonide glaukoniidisisalduse ja mineraali osahulga kohta. Glaukoniit on koondunud peamiselt kivimit mittemoodustavatesse fraktsioonidesse, mis osutab settematerjali juurdekande lahjendavale mōjule kivimi glaukoniidisisalduse kujundamisel. Erandina pōhjustab suuremat sisaldust kivimi pöhifraktsioonides intensiivne autigeenne mineraaliteke (näiteks lükati basseinis). Mineraali mass on jaotunud valdavalt kahe fraktsiooni - peenaleuriidi ja peene liiva vahel. 
88

M. Paten

M. RATTSEP

DISTRIBUTION OF GLAUCONITE IN GRAIN SIZE FRACTIONS OF ESTONIAN LOWER CAMBRIAN ROCKS

Fifty-six samples from different types of sedimentary rocks of Lontova, Lükati and Tiskre formations were studied in order to determine the quantitative distribution of glauconite between more than $0.01 \mathrm{~mm}$ grain size fractions. Fractions greater than $1.0,0.5-1.0,0.25-0.5,0.1-0.25,0.05-0.1,0.01-0.05 \mathrm{~mm}$ were investigated under microscope and binocular microscope after separating pelitic parts from rocks and sifting (Fig. 1).

Amounts of glauconite were found with the help of the approximate calculation method given by L. Rukhin (1961). Comparison of the glauconite content in single fractions with grain size distribution of rocks (Fig. 2) showed that we c rn meet the greatest mineral contents in non-rockforming fractions, which is due to the diluting effect of sediment influx. As an exception, the greatest mineral contents may occur in main grain size fractions if authigenic mineral formation was intensive as, for example, in Lükati Basin.

The mineral amount is prevalently distributed between fine silt and (fine) sand fractions of rocks. 